\title{
Massachusetts considering payment reform
}

Published at www.cmaj.ca on Sept. 23.

$\mathrm{I}$ t doesn't get bleeped out on network television, but the term "capitation" is nonetheless considered a bad word in some parts of the United States. Perhaps that's why proponents of payment reform in Massachusetts, which is poised to become the first state to completely shift its health care system from fee-for-service to capitation, favour the term "global payment." Whatever they call it, the members of the Massachusetts Special Commission on Payment Reform say it's the best option for controlling the ever-expanding cost of health care.

"When you look at health care spending in the United States, it's growing at rates that are far in excess of wages and general inflation, and that's a problem," says Sarah Iselin, commissioner of the Massachusetts Division of Health Care Finance and Policy, who cochaired the commission. "I think we are seeing, not just here but in other states and at the national level, a real consensus building about the need to tackle the way we pay for health care."

The commission met several times in the spring and summer, and has recommended that Massachusetts, which already pays about $20 \%$ of its doctors through some form of capitation, completely transition to global payment over a five-year period ending in 2015. Some have estimated that this change could save the state US\$50 billion over 10 years.

In a capitation system, health care providers receive a set amount of money per patient for a given period. This gives doctors a financial stake in reducing costs, which, proponents claim, will lead to a reduction in unnecessary services. (Doctors have been known to order tests and procedures only to ensure they won't later be sued, a practice known as "defensive medicine.") It would, on the other hand, likely lead to an increase in services that are effective but may be unpopular with physicians because of

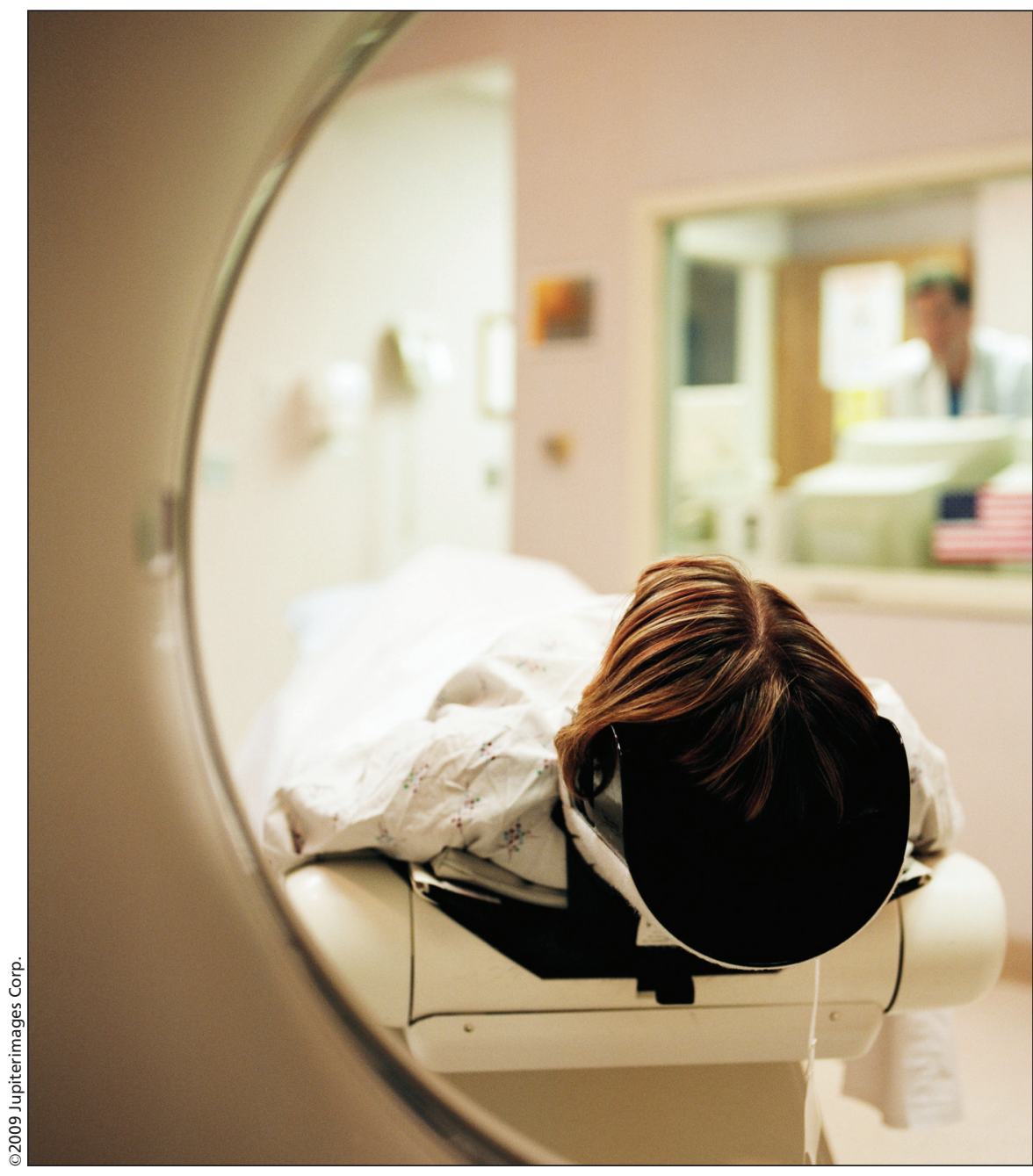

Supporters of the global payment model for health care in Massachusetts say it will reduce the number of expensive but unnecessary tests performed on patients, but critics say it will restrict patients' choice of treatment options.

low profit margins, such as preventative care measures. Fee-for-service providers, by contrast, may be less likely to consider cost effectiveness because they have a financial incentive to order costly tests and procedures even if they aren't absolutely necessary.

Capitation supporters also claim it gives physicians the option of spending more time with complex patients without worry of losing several billable appointments. Plus it frees doctors from the persistent need to earn fees, so they can coordinate care with other health professionals without losing income.

"Payment reform is just a lever," says Iselin. "We are using payment as a means of nudging the delivery system to start working together to coordinate care in a way that it doesn't right now."

But a global payment system, critics note, is far from risk-free. Because capitated patients take money out of a physician's pocket every time they walk through the door, doctors might be tempted to court healthier patients, at the expense of those who need help the most. Encouraging physicians to cut 
expenses might also, at times, put them in conflict with patients, who want the best care, not the cheapest. Since budgets will have to be met, patients will most likely experience increased restrictions on their treatment options.

Then there is the question of who should bear the financial risk. Unpredictable expenses, such as care for accident victims or patients that develop chronic illnesses, can add up and sink a medical practice. More than a decade ago, some US health care providers who switched to a global payment model took on all the financial risk and ended up going under. This is why some doctors still cringe upon hearing the word "capitation."

"If you had a patient who had hepatoma and winded up with a liver transplant, you were dinged for the whole thing," says Dr. Alice Coombs, president-elect of the Massachusetts Medical Society and the only physician on the payment reform commission.

To address this concern, the commission recommended that providers not be expected to carry all the finan- cial risk. "It's really important for insurers and the government to know that this is not all on the providers," says Coombs. "Unless that happens, the transition will not succeed."

The commission also recommended that capitation fees for patients be adjusted according to such factors as socio-economic standing and health status. As for worries of physicians avoiding sicker patients or skimping on care to save money, the commission suggested the state create accountable care organizations and monitor core performance measures.

Another barrier to the creation of a global payment system in Massachusetts, or in any other state, is the low percentage of physicians who use electronic medical records. Keeping track of each patient's capitation fee, adjusting fees when necessary, logging performance data, coordinating care with other providers - these and many other administrative tasks require a high-tech infrastructure.

"The fulfillment of the promise to have electronic records and better com- munication between providers - that has to happen regardless of what payment system we use, but you can't even imagine having an effective global payment system without electronic records," says Timothy Gens, executive vice-president of the Massachusetts Hospital Association.

There are many questions that have to be answered before Massachusetts can switch to global payment, Gens notes. How much financial risk will private insurers bear? What role will government play in oversight? Who will pay for the necessary electronic record systems? How will accountable care organizations be formed?

"This is a huge challenge, but we are firmly committed to change," says Gens. "We think there too many things wrong with the status quo to defend it. There are some good parts, but it doesn't work well enough for those who provide care, for those who need care or for those who pay for care." Roger Collier, CMAJ

DOI:10.1503/cmaj.109-3058 